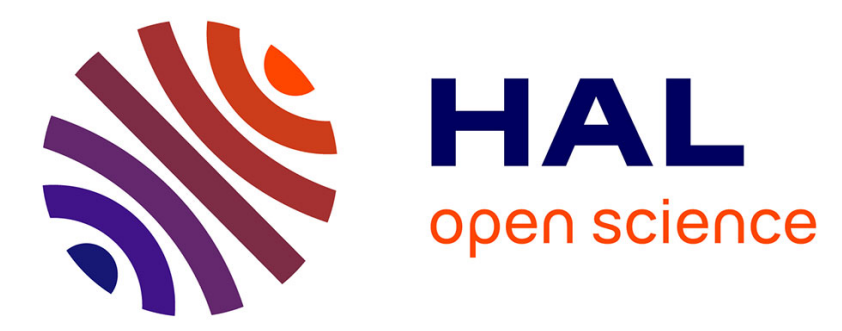

\title{
Nonlinear field dependent conductivity dielectrics made of graphite nanoplatelets filled composites
}

Renaud Metz, Christophe Blanc, Sébastien Dominguez, Said Tahir, Rozenn

Le Parc, M. Hassanzadeh

\section{- To cite this version:}

Renaud Metz, Christophe Blanc, Sébastien Dominguez, Said Tahir, Rozenn Le Parc, et al.. Nonlinear field dependent conductivity dielectrics made of graphite nanoplatelets filled composites. Materials Letters, 2021, 292, pp.129611. 10.1016/j.matlet.2021.129611 . hal-03245508

\author{
HAL Id: hal-03245508 \\ https://hal.science/hal-03245508
}

Submitted on 18 Nov 2021

HAL is a multi-disciplinary open access archive for the deposit and dissemination of scientific research documents, whether they are published or not. The documents may come from teaching and research institutions in France or abroad, or from public or private research centers.
L'archive ouverte pluridisciplinaire HAL, est destinée au dépôt et à la diffusion de documents scientifiques de niveau recherche, publiés ou non, émanant des établissements d'enseignement et de recherche français ou étrangers, des laboratoires publics ou privés.

\section{(1) (1) $\$$}

Distributed under a Creative Commons Attribution - NonCommercial - NoDerivatives $\mid 4.0$ 


\title{
Nonlinear Field Dependent Conductivity Dielectrics made of Graphite Nanoplatelets Filled Composites
}

R. Metz*, C. Blanc, S. Dominguez, S. Tahir, R. Leparc

Laboratoire Charles Coulomb UMR 5221 CNRS-Université de Montpellier

(Université Claude Bernard - Lyon 1)

Place Eugène Bataillon, Bâtiment 11, Montpellier, France

E-mail: renaud.metz@gmail.com

M. Hassanzadeh

Schneider Electric

37 Quai Paul Louis Merlin, 38000 Grenoble, France

\begin{abstract}
Downsizing electronic and electric equipment requires the optimization of electric field distributions in order to avoid localized dielectric breakdown (also called partial discharges). This paper presents a novel dielectric composite material aimed at grading electrical local surface stress. This functional material has a conductivity which increases by several orders with the applied electric field giving the ability to distribute the field by itself. It is prepared for the first time by dispersing graphite nanoplatelets in a polymer and may be used as a resistive or capacitive field grading material in electronic and electrical applications. Mechanisms at the origin of the nonlinear behavior are discussed.
\end{abstract}

Keywords: carbon materials, composite materials, field grading material, nonlinear composite materials, dielectrics, graphite nanoplatelets

\section{Introduction}

Electric field control is a main issue in the elaboration of electric or electronic devices [1-5]. Indeed, the increase of energy demand with the concomitant decrease of the size of electric devices implies additional electric stresses on voltage insulating systems [6-8]. This makes it ever more technically challenging to safely and durably provide an efficient insulation. In fact, intense electric fields can generate partial discharges in air or in the electrical insulation, resulting in accelerated aging or dielectric breakdown. The dimensioning and geometry of 
electrical systems are therefore optimized to prevent or limit any intensification of the electric field in risk areas, known as "triple points" (a triple junction where three materials with three permittivities meet) [1]. There are several possible solutions to address the problem of mastering the field or more accurately, homogenizing it by grading evenly the distribution of electric potential. One solution is to use a nonlinear resistive field material, usually a dimmer composite material which changes its conductivity $(\sigma)$ with the electrical field. This work aims at presenting a novel nonlinear composite material made of graphite nanoplatelets randomly dispersed in a thermoset and appreciate its performances for medium voltage applications.

Nano-sheets have driven attention since pioneering works focused on nanocomposites made of monolayers of graphene oxide (GO) previously slightly thermally reduced [9-10]. The switching field, above which there is a departure from an ohmic behavior, can be modulated by the GO reduction rate up to an elemental $\frac{\mathrm{C}}{\mathrm{O}} \sim 7.55$ at $220^{\circ} \mathrm{C}$ [11]. Recently, Gaska et al. prepared nanocomposites from graphite nanoplatelets $(\mathrm{GnP})$ dispersed and oriented by extrusion in low-density polyethylene $[12,13]$. A nonlinear behavior was observed at very high fields $\sim 20 \mathrm{MV} \cdot \mathrm{m}^{-1}\left(20 \mathrm{kV} \cdot \mathrm{mm}^{-1}\right)$. This result was somehow surprising since these fillers do not exhibit surface oxide groups comparable to the ones found in GO, neither in quality nor in density. In this paper, novel composites are prepared by random dispersion of graphite nanoplatelets in a silicone matrix. Dielectric measurements reveal that a fair increase of the conductivity is also observed with the electric field.

\section{Experimental details}

The silicone matrix is the Bluestar RTV141 resin. The graphite nanoplatelets $(\mathrm{GnP})$ fillers were purchased from XG Sciences in powder form (primary particles around $25 \mu \mathrm{m}$ with mean thickness around $6 \mathrm{~nm}$ ). 
The GnP fillers were dispersed under primary vacuum $(\sim 400 \mathrm{~Pa})$ in the silicone matrix by dual asymmetric centrifugal mixing. Thick films of dimensions $110 \mathrm{~mm}$ x $77 \mathrm{~mm} \times 1 \mathrm{~mm}$ were prepared by compression molding at $15 \mathrm{MPa}$ followed by a curing at $150^{\circ} \mathrm{C}$ during 1 hour.

The current-voltage characteristics of the samples $(1 \mathrm{~mm}$ thick, flat cylinders of diameter about $5.4 \mathrm{~cm}$ ) were measured in the range $0-1 \mathrm{kV}$ with a guarded cell connected to a high voltage DC power supply and a Keithley electrometer 6517B. After a first polarization at $1 \mathrm{kV} . \mathrm{mm}^{-1}$, polarization and depolarization measurements are carried out for a duration of 1 hour for the neat polymer matrix and 30 minutes for the GnP-based composites.

\section{Results and Discussion}

Fig. 1 displays the change of conductivity of the GnP based composites as a function of the electrical field for an increasing volume fraction of fillers. The neat silicone resin and lowfilled composites (1-3 wt.\%) are insulators with a conductivity in the range of $10^{-16}-10^{-14} \mathrm{~S}^{-} \mathrm{m}^{-}$ ${ }^{1}$ and a slight drop of conductivity is observed at high electric fields. Surprisingly, these composite materials exhibit a lower conductivity than that of the pristine silicone matrix. This result is not intuitive since the graphite nanoplatelets are conductive (through and in-plane conductivities: $10^{2}$ and $10^{7} \mathrm{~S} . \mathrm{m}^{-1}$, respectively) [12]. Adding such fillers in an insulating matrix should a priori lead to an increase of the conductivity. However, such macroscopic behavior has already been reported $[9,14-15]$ and attributed to ionic transport disturbed by nanoplatelets network [9], trapping of charge carriers in deep traps [14] or invoked as an electronic Coulomb blockade phenomenon [15]. On the other hand, the electrical behavior drastically changes for filler concentrations above $4 \mathrm{wt} . \%$ and is typical of that of percolated composites.

Fig. 2 compares the data of the most loaded sample (5wt.\%) with the data from References $[9,13]$. The GnP based composite shows a switching field about $3 \cdot 10^{4} \mathrm{~V} \cdot \mathrm{m}^{-1}$, which is 2 orders of magnitudes lower than GO-based nanocomposites $\left(\sim 10^{6} \mathrm{~V} \cdot \mathrm{m}^{-1}\right)$. Above this field, the 
conductivity behaves $\sigma \propto E^{\alpha}$, where $\alpha \sim 3$ is much lower than for GO-based nanocomposites ( $\alpha \sim 10)$. Fig. 2 also depicts the conductivity of the GnP-based composite discussed in [13]. The low-density polyethylene extrusion results in the alignment of the GnP fillers and the electric measurements have been carried out in a direction perpendicular to the extrusion direction. The conductivity is about 6 orders of magnitude lower. Extruded samples show $\alpha \sim 4$ which suggests that the orientation of the GnP does not influence the nonlinearity; only the switching field ( $\left.2.10^{7} \mathrm{~V} \cdot \mathrm{m}^{-1}\right)$ is affected.

The pioneer work [9] advocated that abundant surface oxide groups such as carbonyl groups [11,16-18] are located on the edges of the reduced GO monolayers (1.1nm thick), lead to a disrupted $\mathrm{sp}^{2}$ carbon structure and act as barrier voltages. Thus adjusting the GO oxidation state can affect the energy barriers from these surface edge groups, tune the intrinsic fielddependent conductivity of GO, and eventually change the switching voltage of the nanocomposite at the macroscopic scale. Here, the concentration of oxide groups in GnP is low since oxygen was not detected by elemental analysis which found (in at.\%) : C : 96.57, $\mathrm{N}: 1.36$, $\mathrm{H}: 1.74$ and $\mathrm{S}: 0.33$ [19] and probably cannot explain the observed behavior. Here, the origin of the macroscopic nonlinear properties might also come from a specific percolating or density (close neighbors) architecture made of the coexistence of aggregates and single nanoplatelets. The study of the effects of additional parameters (such as temperature or pressure (ref ..)) on the properties of the composites could help to gain more insights in the underlying mechanisms.

\section{Conclusion}

In conclusion, graphite nanoplatelets filled silicon composites are found to possess nonlinear resistive behaviors with a conductivity typical of percolated composites. At about 4 wt.\% of nanofillers, a field-dependent conductivity variation of 6 orders of magnitude is observed. GnP loaded composites exhibit similar properties than GO-based nanocomposites 
but with a less sharp transition and a switching field 2 orders of magnitude lower. At low field, composites of graphite nanoplatelets exhibit conductivity one order lower than that the neat polymer matrix. The exact mechanisms at the origin of the non-linearity in these composites is not yet fully determined and will require additional experiments.

\section{Acknowledgement}

The authors appreciate the financial supports provided by Occitanie Prematuration 2017 Tension 006684 ESR_PREMAT-000021 (S. Dominguez, Post-Doc) and by Schneider Electric to the training of B. Dejean on Flux 2D (Thesis) and would also like to thank them for helping to the preparation of the samples and part of their characterization.

\section{References}

[1] T. Christen, L. Donzel, F. Greuter, Nonlinear Resistive Electric Field Grading Part 1: Theory and Simulation, IEEE Electrical Insulation Magazine 26(6) (2010) 4759.https://doi.org/10.1109/MEI.2010.5599979

[2] C. Liu, Y. Zheng, B. Zhang, X. Zheng, S. Hu, K. Han, Review of Nonlinear Conductivity Theory Research of Modified Composite Materials, IEEE Access 7 (2019) 50536-48. https://doi.org/10.1109/ACCESS.2019.2906662

[3] G. Mazzanti, J. Castellon, G. Chen, J.C. Fothergill, M. Fu, N. Hozumi, J.H. Lee, J. Li, T. Marsinotto, F. Fauseth, P. Morshuis, C. Reed, I. Troia, A. Tzimas, K. Wu, The Insulation of HVDC Extruded Cable System Joints. Part 1: Review of Materials, Design and Testing Procedures, IEEE Transactions on Dielectrics and Electrical Insulation 26(3) (2019) 964-72. https://doi.org/10.1109/TDEI.2019.007916

[4] H. Ye, T. Fechner, X. Lei, Y. Luo, M. Zhou, Z. Han, H. Wang, Q. Zhuang, R. Xu, D. Li, Review on HVDC cable terminations, High Voltage, IET journals, The institution of Engineering and Technology 3(2) (2018) 79-89. https://doi.org/10.1049/hve.2017.0144

[5] H. Hourdequin, L. Laudebat, M. Locatelli, P. Bidan, Contribution à la conception de structures de packaging pour les modules de puissance très haute tension : contraintes sur les isolants, IEEE International Conference on Dielectrics (ICD) Symposium de génie électrique (SGE 2016) : EF-EPF-MGE 2016, 7-9 June 2016, Grenoble, France.

[6] C. Li, C. Lin, J. Hu, L. Weidong, Q. Li, B. Zhang, S. He, Y. Yang, F. Liu, J. He, Novel HVDC Spacers by Adaptively Controlling Surface Charges-Part I: Charge Transport and Control Strategy, IEEE Transactions on Dielectrics and Electrical Insulation 25(4) (2018) 1237-66. https://doi.org/10.1109/TDEI.2018.007054 
[7] A. Naeini, E. Cherney, S. Jayaram, Modified Stress Grading System for a $13.8 \mathrm{kV}$ Inverter-Fed Rotating Machine, IEE Transactions on Dielectrics and Electrical Insulation 26(4) (2019) 1261-69. https://doi.org/10.1109/TDEI.2019.007991

[8] C. Staubach, T. Hildinger, A. Staubach, Comprehensive Electrical and Thermal Analysis of the Stress Grading System of a Large Hydro Generator, IEEE Electrical Insulation Magazine 34(1) (2018) 37-49. https://doi.org/10.1109/MEI.2018.8246120

[9] Z. Wang, J.K. Nelson, H. Hillborg, S. Zhao, L.S. Schadler, Graphene Oxide Filled Nanocomposite with Novel Electrical and Dielectric Properties, Advanced Materials 24(23) (2012) 3134-43. https://doi.org/10.1002/adma.201200827

[10] Z. Wang, J.K. Nelson, H. Hillborg, S. Zhao, L.S. Schadler, Nonlinear Conductivity and Dielectric Response of Graphene Oxide Filled Silicone Rubber Nanocomposites, Annual Report Conference on Electrical Insulation and Dielectric Phenomena (2012) 40-43. https://doi.org/10.1109/CEIDP.2012.6378717

[11] W. Li, U.W. Gedde, H. Hillborg, Structure and electrical properties of silicone rubber filled with thermally reduced graphene oxide, IEEE Transactions on Dielectrics and Electrical Insulation 23(2) (2016) 1156-63. https://doi.org/10.1109/TDEI.2015.005485

[12] K. Gaska, X. Xu, R. Kádár, B. Ganjipour, A. Yurgens, S. Gubanski, S. Influence of manufacturing process on electrical properties of LDPE-GnP Nanocomposites, Proceedings of the Nordic Insulation Symposium (2017) 25.

[13] K. Gaska, X. Xu, S. Gubanski, R. Kádár, Electrical, Mechanical, and Thermal Properties of LDPE Graphene Nanoplatelets Composites Produced by Means of Melt Extrusion Process, Polymers 9(1) 11 (2017) 1-12. https://doi.org/10.3390/polym9010011

[14] M. Wåhlander, F. Nilsson, R.L. Andersson, A. Carlmark, H. Hillborg, E. Malmström, Reduced and Surface-Modified Graphene Oxide with Nonlinear Resistivity, Macromolecular Rapid Communications 38(16) (2017) 1700291 1-7. https://doi.org/10.1002/marc.201770052

[15] S. Diaham, E. Pizzutilo, L. Da Gama Fernandes Vieira, Z. Valdez Nava, J.-Y. Chane Ching, E. Flahaut, D. Fabiani, Novel Electrical Conduction Properties Obtained in Few-Layer Graphene/Epoxy Nanocomposites, IEEE International conference on Nanotechnology, July 27-30 (472) (2015).

[16] I. Jung, D. Dikin, R. Piner, R. Ruoff, Tunable Electrical Conductivity of Individual Graphene Oxide Sheets Reduced at "Low" Temperatures, Nano Lett. 8(12) (2008) 4283-87. https://doi.org/10.1021/n18019938

[17] C. Gomez-Navarro, R. Weitz, A. Bittner, M. Scolari, M. Mews, M. Burghard, K. Kern, Electronic Transport Properties of Individual Chemically Reduced Graphene Oxide Sheets, Nano Lett. 7(11) (2007) 3499-3503. https://doi.org/10.1021/n1072090c

[18] B. Ghavami, A. Rastkar-Ebrahimzadeh, Varistor characteristics of a nano-device containing graphene and oxidised graphene: verification by DFT + NEGF, Molecular Physics 113(23) (2015) 3696-702.https://doi.org/10.1080/00268976.2015.1053549 
[19] L. Diaz-Chacon, R. Metz, P. Dieudonne-George, J.-L. Bantignies, S. Tahir, M. Hassanzadeh, R. Atencio, R., Graphite Nanoplatelets Composite Materials: Role of the Epoxy-System in the Thermal Conductivity, Journal of Materials Science and Chemical Engineering 3 (2015) 75-87. https://doi.org/10.4236/msce.2015.35009 


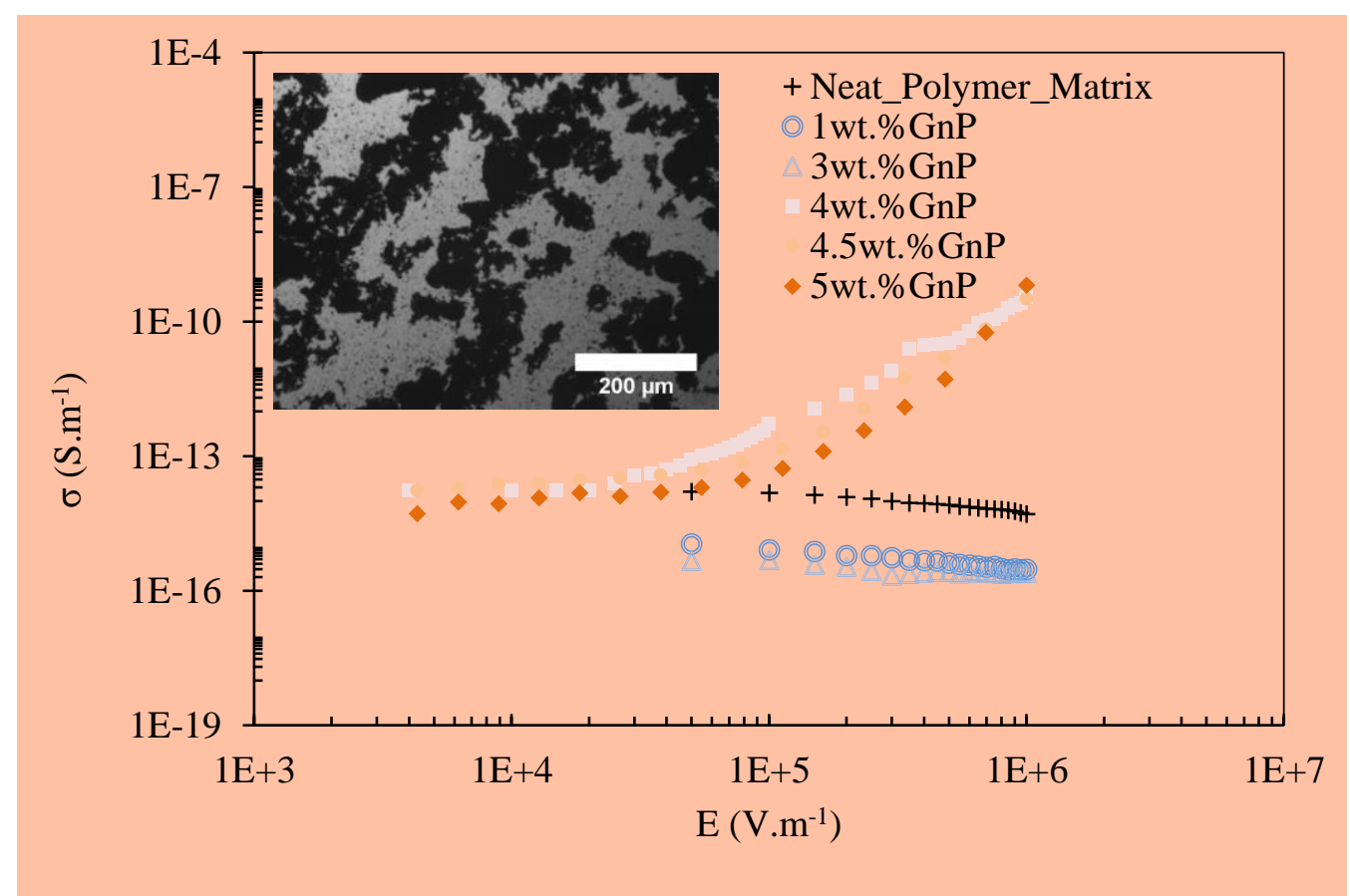

Fig. 1. Plot of conductivity with respect to field strength for GnP_based composites with different loading of graphite nanoplatelets. Inset : Optical microscopy of the specimen $4.5 \mathrm{wt} . \%$ shows the coexistence of micronic aggregates in a grey background filled of isolated primary nanoplatelets.

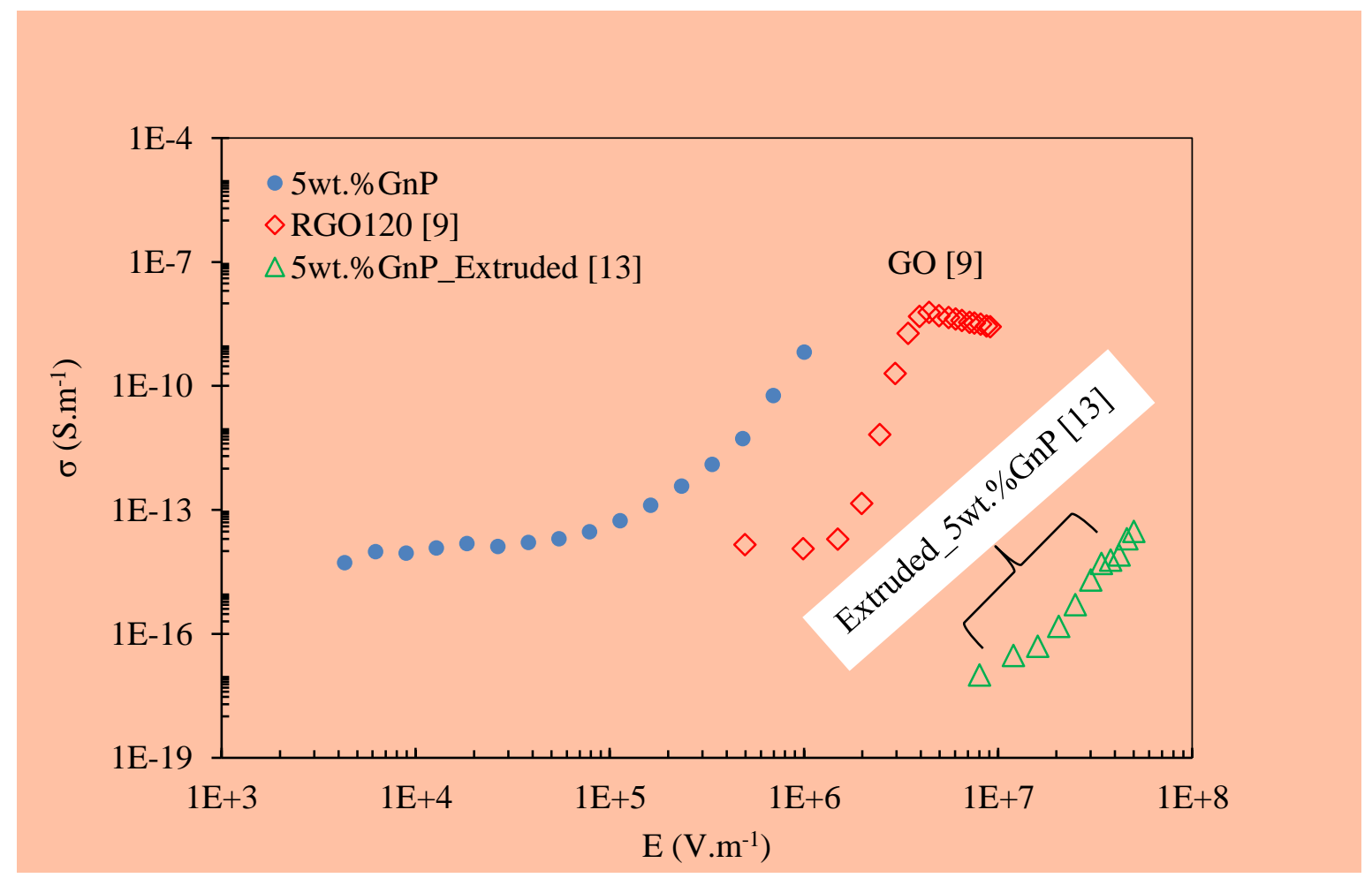

Fig. 2. Typical conductivity-field dependency of a GnP-based composite compared with two series of samples from the literature: slightly thermally reduced graphene oxide at $120^{\circ} \mathrm{C}$ 
(empty diamonds) [9] and in a direction perpendicular to the extrusion direction at high field (empty triangles) [13]. 